\title{
Influence of Elective versus Emergent Hospital Admission on Patient Satisfaction
}

\author{
Joshua J. Fenton, MD, MPH, Anthony F. Jerant, MD, and Peter Franks, MD
}

Background: Patient satisfaction is increasingly used as a health care quality metric, although satisfaction has been associated with more intense health care, including hospitalization. Whether the increased hospitalization associated with satisfaction is limited to elective (often discretionary) hospitalization is unknown.

Methods: We conducted a prospective cohort study of adult respondents to the 2000 to 2010 US National Medical Expenditure Panel Survey $(\mathrm{N}=50,978)$, including 2 years of panel data for each subject. Patient sociodemographics, health status, and hospital use were assessed in year 1, with hospital use categorized as elective or emergent hospitalization (based on whether it was preceded by an emergency visit). Year 2 patient satisfaction with health care providers was assessed using 5 items from the Consumer Assessment of Health Plans Survey. We used ordinal logistic regression to estimate adjusted associations between year 1 hospitalization and year 2 patient satisfaction quartile.

Results: Adjusting for sociodemographics, insurance status, availability of a usual source of care, chronic disease burden, health status, and year 1 office and prescription drug utilization, having $\geq 1$ elective hospitalizations in year 1 was associated with higher year 2 satisfaction quartile (adjusted odds ratio $[\mathrm{OR}], 1.21 ; 95 \%$ confidence interval $[\mathrm{CI}], 1.11-1.32)$. Emergent hospitalizations in year 1 were not associated with satisfaction quartile in year 2 (adjusted OR, 1.01; 95\% CI, 0.91-1.12).

Conclusion: In a nationally representative sample, elective (but not emergent) hospitalizations were associated with subsequently higher overall satisfaction with health care providers, suggesting a nexus between discretionary hospital use and patient satisfaction. (J Am Board Fam Med 2014;27:249-257.)

Keywords: Delivery of Health Care, Health Care Systems, Patient Satisfaction, Physician-Patient Relations, Utilization

There is currently intense interest in instituting satisfaction as a measure of patient-centered quality of care. Medicare-certified hospitals must publicly report standardized metrics of patient satisfaction, ${ }^{1}$ and payers are increasingly adjusting hospital and provider reimbursements based on these metrics. ${ }^{2}$ On its Physician Compare website, Medicare will soon report patient satisfaction metrics for primary care and other ambulatory providers. A principal

This article was externally peer reviewed.

Submitted 7 June 2013; revised 1 October 2013; accepted 3 October 2013.

From the Department of Family and Community Medicine and Center for Healthcare Policy and Research, University of California, Davis, Sacramento.

Funding: none.

Conflict of interest: none declared.

Corresponding author: Joshua Fenton, MD, MPH, Department of Family and Community Medicine, University of California, Davis, 4860 Y Street, Suite 2300, Sacramento, CA 95817 (E-mail: Joshua.fenton@ucdmc.ucdavis.edu). goal of Ontario's Excellent Care for All initiative is to enhance patient satisfaction in both hospital and ambulatory settings.

Patient-centered communication may enhance patient satisfaction. ${ }^{3-9}$ At the same time, patient satisfaction has been consistently associated with the fulfillment of patient requests, ${ }^{10,11}$ and clinicians have expressed concern that incentives to maximize satisfaction may lead to excessive testing or treatment in attempts to satisfy patients. ${ }^{12-14}$ Research also suggests that higher satisfaction may be associated with more care and higher mortality, ${ }^{15,16}$ raising the possibility that the greater intensity of care may be for discretionary, possibly harmful tests or treatments. ${ }^{17,18}$ To the extent that satisfaction is associated with greater intensity of care, especially discretionary care, efforts to encourage higher levels of patient satisfaction may have untoward cost and health effects. Better understanding of this potential problem is warranted. 
Variation in hospitalization rates contributes significantly to regional differences in care intensity, ${ }^{19,20}$ presumably reflecting variation in discretionary hospital-based care. While emergency admissions may also be discretionary, nonemergency hospital admissions would seem more likely to be either elective or to have a discretionary component. In a national Medicare sample, one third of admissions did not originate from emergency departments and were classified as elective. ${ }^{21}$ Common reasons for elective admissions in this Medicare cohort were joint or orthopedic surgeries and cardiac and vascular procedures. ${ }^{21}$ In a prior study we observed that higher satisfaction was associated with higher rates of hospitalization, ${ }^{15}$ but that study did not distinguish between emergent and elective hospitalization.

In this study we address the question, Are elective (as opposed to emergent) hospitalizations distinctly associated with higher satisfaction? We used data from the US Medical Expenditure Panel Survey (MEPS) to assess the relationship between emergent hospitalizations (hospitalizations with preceding emergency visits) and elective hospitalizations (hospitalizations without preceding emergency visits) and subsequent satisfaction among a nationally representative sample of US adults. We hypothesized that higher satisfaction would be associated with elective but not emergent hospitalization.

\section{Methods}

\section{Design, Setting, and Subjects}

We conducted a prospective cohort study using 2000 to 2010 MEPS data. The MEPS is an annual, nationally representative survey of the US noninstitutionalized civilian population and uses an overlapping panel design. ${ }^{22}$ Participants are interviewed repeatedly regarding their health status and health care over a 2-year period. We included respondents $\geq 18$ years old with one or more doctor visits in each of the 2 panel years and who reported on satisfaction with their physician and overall health care in year 2. Response rates during the study years ranged from $58.6 \%$ to $70.5 \%$.

\section{Satisfaction With Health Care Providers}

Patients enrolled in MEPS reported on their satisfaction with their health care providers by responding to items from the Consumer Assessment of Health Plans Survey (CAHPS). Using previously described methods, ${ }^{15}$ we constructed a standardized scale measuring year 2 patient satisfaction based on 4 CAHPS items regarding doctor communication and one in which patients rated their health care from all doctors and providers on a scale of 0 to 10 (from the "worst" to the "best"). These 5 items correlate strongly with other CAHPS dimensions and global satisfaction. ${ }^{23}$ Cronbach $\alpha$ for the 5 items was 0.88 , reflecting high internal consistency. We classified patients for analyses by quartile of satisfaction.

\section{Emergent versus Elective Hospitalization}

During each survey round, the MEPS collects information regarding hospitalizations, emergency department visits, and whether hospitalizations were preceded by emergency visits. We used these data to specify whether participants had any nonobstetric hospitalizations in year 1, classifying hospitalizations as emergent if they were preceded by an emergency visit and elective if they were not. While utilization data are self-reported, the MEPS validates and verifies these data using standardized medical record review among a subsample of respondents. Because the MEPS lacks detailed information regarding reasons for hospitalization, we could not definitively classify hospitalizations as either avoidable or inappropriate.

\section{Covariates}

We identified the following additional patient characteristics in year 1, grouped as sociodemographics, health behaviors, access, propensity to use care, and health status. All these measures are included in the MEPS data files. Sociodemographics included age; sex; race/ethnicity (black, white, Hispanic, or other); Census region (West, Midwest, Northeast, South); household income ( $<100 \%$, $100-124 \%, 125-199 \%, 200-399 \%$, or $\geq 400 \%$ of the federal poverty level); education (less than high school, some high school, high school graduate, some college, college graduate); and urban residence. We measured access through health insurance status (uninsured, privately insured, or publicly insured) and access to a usual source of care.

We assessed morbidity through a count of 8 self-reported chronic conditions (diabetes, hypertension, coronary heart disease, myocardial infarction, cerebrovascular disease, asthma, emphysema, and arthritis). We used the Medical Outcomes Study 12-item Short Form (SF-12) mental and 
physical component summaries as measures of mental and physical health status, respectively, ${ }^{24,25}$ and as indirect measures of illness severity. ${ }^{26} \mathrm{We}$ also included a single-item, self-rated health measure in which patients rate their health as excellent, very good, good, fair, or poor; this predicts inpatient utilization independent of the SF-12. ${ }^{27}$ To address otherwise unmeasured morbidity and propensity to use care, we included the number of outpatient visits and drug prescriptions.

\section{Analyses}

Primary analyses used proportional odds ordinal logistic regression analyses to examine associations between year 1 patient covariates, including elective or emergent hospitalization, and year 2 satisfaction quartile. Because there are no formal tests of the soundness of the proportional odds assumption in the setting of complex survey data, we also conducted a series of simple logistic regression analyses with the year 2 satisfaction outcome dichotomized at each quartile breakpoint (quartile 4 vs lower quartiles, quartiles 3 and 4 vs lower quartiles, and quartiles 2 to 4 vs the lowest quartile) as a function of hospitalization and covariates. The similar results, regardless of satisfaction breakpoint, supported the soundness of the ordinal (proportional odds) model. Because of consistent findings across breakpoints, we therefore present only the primary ordinal analysis and the results of the simple logistic model predicting highest year 2 satisfaction (quartile 4) versus lower year 2 satisfaction (quartiles 1-3). To facilitate interpretation, parameter estimates for the logistic regression analysis also are presented as predictive margins. ${ }^{28}$ Last, we used multinomial logistic regression to model satisfaction quartile as a function of hospitalizations and covariates. Because the multinomial findings were consistent with the ordinal logistic regression, we present only the latter. STATA/MP software version 12.1 (StataCorp, College Station, TX) were used, adjusting for the complex survey design, yielding nationally representative parameter estimates and appropriate standard errors, and adjusting for the nesting of respondents within each survey year.

\section{Results}

\section{Patient Characteristics}

Of 107,734 adult respondents entering the 2000 to 2009 MEPS and participating for 2 years, 66,997 had year 2 satisfaction data and 50,978 had complete year 1 and year 2 data and were included in the analysis. During year 1, 8.6\% of patients were hospitalized, $4.9 \%$ electively and $4.5 \%$ emergently. Compared with nonhospitalized patients, hospitalized patients were older, had less education and income, and were in poorer physical and mental health (Table 1). Compared with patients with emergent hospitalizations, patients with elective hospitalizations were more likely female, white, had higher education and income, better self-rated health, and higher satisfaction in year 2. We do not report overall or pairwise tests of significance comparing unadjusted patient characteristics by year 1 hospitalization status because many tests would be statistically significant because of the large sample sizes rather than the magnitude of differences.

\section{Predictors of Satisfaction}

In proportional odds ordinal logistic regression analyses, higher satisfaction in year 2 was associated with older age, black race, lower educational status, and having private or public health insurance (vs none) (Table 2). Higher satisfaction in year 2 also was associated with having a usual source of care, better physical and mental health status, and excellent self-rated health.

With regard to health care utilization in year 1 , higher satisfaction in year 2 was associated with receiving more drug prescriptions in year 1 and having been hospitalized electively (adjusted odds ratio, $1.21 ; 95 \%$ confidence interval, 1.11-1.32). Satisfaction in year 2 was not associated with emergent hospitalization in year 1 (adjusted odds ratio, 1.01; 95\% confidence interval, 0.91-1.12).

Results were consistent in logistic regression analyses assessing the likelihood of being in the highest year 2 satisfaction quartile compared with lower quartiles (Table 3). After adjusting for covariates, $32.1 \%$ of patients with $\geq 1$ elective hospitalization in year 1 were in the highest year 2 satisfaction quartile, compared with $27.8 \%$ of patients without elective hospitalizations $(P<.001)$.

\section{Discussion}

Within a nationally representative US sample, we found that elective hospitalization was associated with higher patient satisfaction with health care providers in the subsequent year, whereas emergent hospitalization was not. Our findings are con- 
Table 1. Characteristics of Medical Expenditure Panel Survey Respondents by Year 1 Hospitalization, 2000 to 2009*

\begin{tabular}{|c|c|c|c|c|}
\hline \multirow[b]{2}{*}{ Characteristics } & \multicolumn{3}{|c|}{ Hospitalizations in Year 1} & \multirow[b]{2}{*}{$\begin{array}{c}\text { Overall } \\
(\mathrm{n}=50,978 ; 100 \%)\end{array}$} \\
\hline & $\begin{array}{c}\text { None } \\
(\mathrm{n}=46,356 ; 91.4 \%)\end{array}$ & $\begin{array}{c}\geq 1 \text { Elective } \\
(\mathrm{n}=2,584 ; 4.9 \%)\end{array}$ & $\begin{array}{c}\geq 1 \text { Emergent } \\
(\mathrm{n}=2,515 ; 4.5 \%)\end{array}$ & \\
\hline \multicolumn{5}{|c|}{ Year 2 patient satisfaction quartile } \\
\hline First (least satisfied) & 21.9 & 21.2 & 24.4 & 21.9 \\
\hline Second & 26.8 & 27.5 & 27.4 & 26.9 \\
\hline Third & 23.5 & 22.2 & 21.1 & 23.3 \\
\hline Fourth (most satisfied) & 27.8 & 29.1 & 27.2 & 27.8 \\
\hline Mean age (years) & 48.1 & 58.0 & 55.4 & 48.7 \\
\hline Female sex & 56.5 & 60.7 & 56.8 & 56.7 \\
\hline \multicolumn{5}{|l|}{ Race/ethnicity } \\
\hline White & 75.6 & 78.6 & 74.8 & 75.7 \\
\hline Hispanic & 9.2 & 7.0 & 8.7 & 9.1 \\
\hline Black & 9.9 & 10.7 & 13.3 & 10.0 \\
\hline Other & 5.4 & 3.8 & 3.2 & 5.2 \\
\hline \multicolumn{5}{|l|}{ Education } \\
\hline$<$ High school & 5.3 & 7.5 & 10.8 & 5.6 \\
\hline Some high school & 9.9 & 12.2 & 15.7 & 10.2 \\
\hline High school graduate & 30.4 & 31.9 & 35.7 & 30.7 \\
\hline Some college & 30.5 & 26.5 & 17.0 & 29.8 \\
\hline College graduate & 30.5 & 26.5 & 17.0 & 29.8 \\
\hline \multicolumn{5}{|l|}{ Household income (\% FPL) } \\
\hline$<100 \%$ & 9.3 & 13.5 & 17.0 & 9.8 \\
\hline $100-124 \%$ & 3.4 & 5.3 & 7.7 & 3.7 \\
\hline $125-199 \%$ & 11.9 & 15.3 & 18.1 & 12.3 \\
\hline $200-399 \%$ & 30.2 & 29.5 & 28.8 & 30.1 \\
\hline$\geq 400 \%$ & 45.1 & 36.4 & 28.4 & 44.1 \\
\hline Urban MSA (vs. nonurban) & 82.2 & 77.2 & 79.7 & 81.9 \\
\hline \multicolumn{5}{|l|}{ Region } \\
\hline Northeast & 19.3 & 16.9 & 19.0 & 19.2 \\
\hline Midwest & 23.2 & 25.1 & 23.6 & 23.3 \\
\hline South & 35.8 & 39.4 & 39.9 & 36.2 \\
\hline West & 21.7 & 18.5 & 17.4 & 21.4 \\
\hline \multicolumn{5}{|l|}{ Insurance coverage } \\
\hline Private insurance & 76.9 & 69.2 & 55.4 & 75.8 \\
\hline Public & 14.7 & 27.3 & 38.1 & 16.1 \\
\hline None & 8.4 & 3.5 & 6.4 & 8.1 \\
\hline Has usual source of care & 85.1 & 91.1 & 91.5 & 85.6 \\
\hline Chronic diseases (mean) ${ }^{\dagger}$ & 1.0 & 2.1 & 1.8 & 1.0 \\
\hline PCS-12 ${ }^{\ddagger}$ (mean score) & 49.0 & 38.1 & 39.5 & 48.1 \\
\hline MCS $-12^{\ddagger}$ (mean score) & 50.6 & 46.7 & 47.8 & 50.4 \\
\hline \multicolumn{5}{|l|}{ Self-rated health } \\
\hline Excellent & 22.8 & 11.1 & 6.5 & 21.7 \\
\hline Very good & 35.5 & 23.4 & 18.7 & 34.4 \\
\hline Good & 28.1 & 31.6 & 30.4 & 28.4 \\
\hline Fair & 10.6 & 20.8 & 27.5 & 11.6 \\
\hline Poor & 2.9 & 13.1 & 16.9 & 3.9 \\
\hline
\end{tabular}

Continued 


\begin{tabular}{|c|c|c|c|c|}
\hline \multirow[b]{2}{*}{ Characteristics } & \multicolumn{3}{|c|}{ Hospitalizations in Year 1} & \multirow[b]{2}{*}{$\begin{array}{c}\text { Overall } \\
(\mathrm{n}=50,978 ; 100 \%)\end{array}$} \\
\hline & $\begin{array}{c}\text { None } \\
(n=46,356 ; 91.4 \%)\end{array}$ & $\begin{array}{c}\geq 1 \text { Elective } \\
(\mathrm{n}=2,584 ; 4.9 \%)\end{array}$ & $\begin{array}{c}\geq 1 \text { Emergent } \\
(\mathrm{n}=2,515 ; 4.5 \%)\end{array}$ & \\
\hline \multicolumn{5}{|l|}{ Healthcare utilization } \\
\hline Office visits, mean & 4.4 & 9.8 & 10.4 & 4.9 \\
\hline Drug prescriptions, mean & 15.2 & 37.8 & 33.4 & 16.7 \\
\hline
\end{tabular}

Data are percentages unless otherwise indicated.

*Means and proportions are population-weighted.

${ }^{\dagger}$ Chronic diseases include diabetes, hypertension, coronary heart disease, myocardial infarction, cerebrovascular disease, asthma, emphysema, and arthritis.

${ }^{\ddagger}$ Scale has a population mean of 50 ; higher scores indicate higher function.

FPL, federal poverty level; MCS-12, 12-item Short Form Mental Component Summary; MSA, metropolitan statistical area; PCS-12, 12-item Short Form Physical Component Summary.

sistent with the hypothesis that greater use of elective (but not emergent) hospital services is related to subsequently higher patient satisfaction. In the US Medicare population, the most common diagnosis-related groups associated with elective hospitalizations include joint and limb surgeries, percutaneous coronary interventions, and vascular procedures such as the insertion of cardiac devices (e.g., pacemakers). ${ }^{21}$ Such procedures often have a discretionary component in that the initiation and timing of these procedures may be driven to some extent by patient or physician preferences rather than evidence-based indications. ${ }^{29,30}$ Meanwhile, clinical trials suggest that patients may be more satisfied (at least in the near-term) with more aggressive hospitalbased treatments than conservative alternatives. ${ }^{31,32}$

While receipt of discretionary care may contribute to higher patient satisfaction with health care providers, we do not believe it is the sole determinant of patient satisfaction. Many features of the health care experience likely contribute to satisfaction with health care providers, including whether care met patients' expectations, ${ }^{11,33-35}$ shorter rather than longer waiting times, ${ }^{36-38}$ and the quality of communication with physician and nonphysician staff. ${ }^{36,38,39}$ In particular, patient-centered communication may enhance the doctor-patient relationship while encouraging efficient, effective care $^{3-8}$ However, it remains unclear whether widely used measures of patient satisfaction capture nuanced dimensions of patient-centeredness, ${ }^{9}$ such as the physician-patient partnership ${ }^{8}$ or physicians' responsiveness to patients' contextual factors or emotions. ${ }^{40,41}$ Our findings nevertheless suggest that some types of health care utilization, in this case elective hospitalization, may increase satisfac- tion. Further study is needed to clarify the relationship between care content and satisfaction with providers, in particular whether satisfaction is associated with the use of lower-value services.

After controlling for hospitalization, higher satisfaction was independently associated with older age, female sex, black race/ethnicity, less education, better health status, having public or private health insurance (rather than no insurance), and having a usual source of care. The associations between older age and better health status and satisfaction have been previously observed, ${ }^{36,42-46}$ although satisfaction may diminish among older adults with multimorbidity. ${ }^{47}$ In addition, satisfaction typically has been associated with less education and lower income ${ }^{36,42,45}$ which together reflect an inverse relationship between socioeconomic status and satisfaction. In most prior research, sex has not predicted satisfaction, ${ }^{36,45}$ whereas black race/ethnicity has predicted lower satisfaction in several prior studies. ${ }^{42,43,45}$ Thus the positive associations between these factors and satisfaction in our nationally representative sample warrant further study. Finally, insurance status and a usual source of care may enhance satisfaction by increasing access to health care.

Strengths of this study include its large, nationally representative sample and the ability to examine a range of sociodemographic, access, and clinical covariates. Nevertheless, associations from this observational study warrant cautious interpretation. It is possible that patients with more trusting patient-physician relationships may be more satisfied, and greater trust may enhance physicians' willingness to admit patients directly into the hospital without preceding emergency visits. Conversely, low satisfaction with providers may reflect 
Table 2. Year 1 Predictors of a Quartile Increase in Year 2 Satisfaction Among Medical Expenditure Panel Survey Respondents, 2000 to $2009(\mathrm{~N}=50,978)^{*}$

\begin{tabular}{|c|c|c|}
\hline Independent Variables & Adjusted OR $(95 \% \mathrm{CI})^{*}$ & $P$ Value \\
\hline$\geq 1$ Elective hospitalizations & $1.21(1.11-1.32)$ & $<.001$ \\
\hline$\geq 1$ Emergent hospitalizations & $1.01(0.91-1.12)$ & .87 \\
\hline Age (per 10 years) & $1.13(1.11-1.14)$ & $<.001$ \\
\hline Female sex & $1.05(1.01-1.09)$ & .01 \\
\hline \multicolumn{3}{|l|}{ Race/ethnicity } \\
\hline White & 1.0 (ref) & - \\
\hline Hispanic & $1.06(0.99-1.14)$ & .09 \\
\hline Black & $1.22(1.15-1.31)$ & $<.001$ \\
\hline Other & $0.78(0.71-0.86)$ & $<.001$ \\
\hline \multicolumn{3}{|l|}{ Education } \\
\hline$<$ High school & 1.0 (ref) & - \\
\hline Some high school & $1.04(0.92-1.14)$ & .46 \\
\hline High school graduate & $1.01(0.93-1.10)$ & .79 \\
\hline Some college & $0.93(0.85-1.01)$ & .10 \\
\hline College graduate & $0.84(0.77-0.92)$ & $<.001$ \\
\hline \multicolumn{3}{|l|}{ Household income (\% FPL) } \\
\hline$<100 \%$ & 1.0 (ref) & - \\
\hline $100-124 \%$ & $1.02(0.90,1.15)$ & .80 \\
\hline $125-199 \%$ & $0.95(0.87-1.03)$ & .22 \\
\hline $200-399 \%$ & $0.93(0.86-1.00)$ & .06 \\
\hline$\geq 400 \%$ & $0.97(0.89-1.06)$ & .56 \\
\hline Urban MSA (vs. nonurban) & $0.95(0.89-1.00)$ & .04 \\
\hline \multicolumn{3}{|l|}{ Insurance coverage } \\
\hline Private insurance & 1.0 (ref) & - \\
\hline Public & $1.06(1.00-1.13)$ & .06 \\
\hline None & $0.79(0.73-0.87)$ & $<.001$ \\
\hline Has usual source of care (vs. none) & $1.29(1.20-1.39)$ & $<.001$ \\
\hline Chronic diseases (per disease) ${ }^{\dagger}$ & $1.02(0.99-1.04)$ & .13 \\
\hline PCS- $12^{\ddagger}$ (per 10 -point increase) & $1.27(1.24-1.30)$ & $<.001$ \\
\hline MCS- $12^{\ddagger}$ (per 10-point increase) & $1.39(1.36-1.42)$ & $<.001$ \\
\hline \multicolumn{3}{|l|}{ Self-rated health } \\
\hline Excellent & 1.0 (ref) & - \\
\hline Very good & $0.75(0.71-0.80)$ & $<.001$ \\
\hline Good & $0.67(0.63-0.71)$ & $<.001$ \\
\hline Fair & $0.68(0.62-0.74)$ & $<.001$ \\
\hline Poor & $0.86(0.75-0.98)$ & .03 \\
\hline \multicolumn{3}{|l|}{ Healthcare utilization } \\
\hline Office visits (per visit) & $1.00(1.00-1.00)$ & .21 \\
\hline Drug prescriptions (per 10) & $1.04(1.03-1.05)$ & $<.001$ \\
\hline
\end{tabular}

*Ordinal logistic regression analyses predicting a quartile increase in year 2 satisfaction. Analyses also adjusted for U.S. region (Northeast, Midwest, South, and West) and Medical Expenditure Panel Survey panel year.

${ }^{\dagger}$ Chronic diseases include diabetes, hypertension, coronary heart disease, myocardial infarction, cerebrovascular disease, asthma, emphysema, and arthritis.

${ }^{\ddagger}$ Scale has a population mean of 50 ; higher scores indicate higher function.

CI, confidence interval; FPL, federal poverty level; MCS-12, 12 -item Short Form Mental Component Summary; MSA, metropolitan statistical Area; OR, odds ratio; PCS-12, 12-item Short Form Physical Component Summary.

dispositional patient characteristics that manifest as a propensity to use emergency departments rather than primary care clinics. These dispositional characteristics might also lead to decreased provider responsiveness to patient preferences or requests for discretionary hospital services. Further research delineating the mechanisms by which satisfaction is correlated with hospital use is needed; some mech- 
Table 3. Logistic Regression Analyses of Year 2 Satisfaction by Year 1 Elective and Emergent Hospitalizations among Medical Expenditure Panel Survey Respondents, 2000 to 2009 ( $\mathrm{N}=50,978)$

\begin{tabular}{lccc}
\hline & \multicolumn{2}{c}{$\begin{array}{c}\text { Patient in Highest Year 2 Satisfaction Quartile (vs. Lower } 3 \\
\text { Quartiles) }\end{array}$} \\
\cline { 2 - 3 } Predictor & Adjusted OR $(95 \%$ CI)* & Adjusted \% (95\% CI)* & $P$ Value \\
\hline Elective hospitalizations in year 1 & $1.0(\mathrm{ref})$ & $27.8(27.2-28.4)$ & $<.001$ \\
0 & $1.24(1.11-1.39)$ & $32.1(29.8-34.4)$ & \\
$\geq 1$ & & $28.0(27.4-28.6)$ & .49 \\
Emergent hospitalizations in year 1 & $1.0(\mathrm{ref})$ & $28.8(26.5-31.1)$ \\
\hline
\end{tabular}

* Odds ratios (ORs) and percentages are adjusted for patient age, sex, education, household income, insurance status, usual source of care, race/ethnicity, geographic region, urban residence, Medical Expenditure Panel Survey panel year, the number of chronic diseases, 12-item Short Form Physical and Mental Component Summary scores, self-rated health, number of office visits, and number of drug prescriptions.

CI, confidence interval.

anisms may imply higher functioning systems, whereas others may suggest inappropriate or unnecessary care.

Our classification of hospitalizations as elective does not definitively establish those hospitalizations as discretionary. Elective hospitalizations may also involve nondiscretionary care, such as urgent direct admission for patients with acute pneumonia or heart failure. However, it is less likely that emergent hospitalizations reflect discretionary care. As such, our findings most likely underestimate any relationship between discretionary hospitalization and satisfaction. In addition, our study's satisfaction measure addressed mainly satisfaction with health care providers, although satisfaction with providers strongly correlates with other satisfaction dimensions. ${ }^{23}$ Although the prospective design of our study is a strength, longitudinal studies could examine the short- and longer-term effects of elective hospitalization (and other factors) on patient satisfaction.

\section{Conclusion}

In a US nationally representative sample, patients who were hospitalized electively expressed greater satisfaction with their health care providers in the following year. While our study confirms prior associations between satisfaction and patient sociodemographics and health status, it also suggests a nexus between discretionary health care utilization, particularly elective hospitalization, and patient satisfaction.

\section{References}

1. Schneider EC, Zaslavsky AM, Landon BE, Lied TR, Sheingold S, Cleary PD. National quality monitoring of Medicare health plans: the relationship between enrollees' reports and the quality of clinical care. Med Care 2001;39:1313-25.

2. Falkenberg K. Why rating your doctor is bad for your health. Forbes, January 21, 2013. Available at: http://www.forbes.com/sites/kaifalkenberg/2013/ 01/02/why-rating-your-doctor-is-bad-for-yourhealth/. Accessed September 23, 2013.

3. Stewart M, Brown JB, Donner A, et al. The impact of patient-centered care on outcomes. J Fam Pract 2000;49:796-804.

4. Bertakis KD, Azari R. Patient-centered care is associated with decreased health care utilization. J Am Board Fam Med 2011;24:229-39.

5. Epstein RM, Franks P, Shields CG, et al. Patientcentered communication and diagnostic testing. Ann Fam Med 2005;3:415-21.

6. Peck BM, Ubel PA, Roter DL, et al. Do unmet expectations for specific tests, referrals, and new medications reduce patients' satisfaction? J Gen Intern Med 2004;19:1080-7.

7. Deyo RA, Diehl AK, Rosenthal M. Reducing roentgenography use. Can patient expectations be altered? Arch Intern Med 1987;147:141-5.

8. Little P, Everitt H, Williamson I, et al. Observational study of effect of patient centredness and positive approach on outcomes of general practice consultations. BMJ 2001;323:908-11.

9. Kupfer JM, Bond EU. Patient satisfaction and patient-centered care: necessary but not equal. JAMA 2012;308:139-40.

10. Kravitz RL, Epstein RM, Feldman MD, et al. Influence of patients' requests for direct-to-consumer ad- 
vertised antidepressants: a randomized controlled trial. JAMA 2005;293:1995-2002.

11. Macfarlane J, Holmes W, Macfarlane R, Britten N. Influence of patients' expectations on antibiotic management of acute lower respiratory tract illness in general practice: questionnaire study. BMJ 1997; 315:1211-4.

12. Elijovich F. Of sommeliers and wine drinkers. Arch Intern Med 2012;172:1111-2; author reply 1113.

13. Zgierska A, Miller M, Rabago D. Patient satisfaction, prescription drug abuse, and potential unintended consequences. JAMA 2012;307:1377-8.

14. Cassel C. No stars for satisfaction ratings. Patient surveys should take a back seat to true measures of clinical skill. Mod Healthc 2008;38:22.

15. Fenton JJ, Jerant AF, Bertakis KD, Franks P. The cost of satisfaction: a national study of patient satisfaction, health care utilization, expenditures, and mortality. Arch Intern Med 2012;172:405-11.

16. Fisher ES, Wennberg DE, Stukel TA, Gottlieb DJ, Lucas FL, Pinder EL. The implications of regional variations in Medicare spending. Part 2: health outcomes and satisfaction with care. Ann Intern Med 2003;138:288-98.

17. Moynihan R, Glasziou P, Woloshin S, Schwartz L, Santa J, Godlee F. Winding back the harms of too much medicine. BMJ 2013;346:f1271.

18. Sirovich BE. How to feed and grow your health care system: comment on "The cost of satisfaction." Arch Intern Med 2012;172:411-3.

19. Newhouse JP, Garber AM. Geographic variation in Medicare services. N Engl J Med 2013;368:1465-8.

20. Fisher ES, Wennberg DE, Stukel TA, Gottlieb DJ, Lucas FL, Pinder EL. The implications of regional variations in Medicare spending. Part 1: the content, quality, and accessibility of care. Ann Intern Med 2003; 138:273-87.

21. McHugh M, Regenstein M, Siegel B. The profitability of Medicare admissions based on source of admission. Acad Emerg Med 2008;15:900-7.

22. Cohen JW, Cohen SB, Banthin JS. The Medical Expenditure Panel Survey: a national information resource to support healthcare cost research and inform policy and practice. Med Care 2009;47(7 Suppl 1):S44-50.

23. Hargraves JL, Hays RD, Cleary PD. Psychometric properties of the Consumer Assessment of Health Plans Study (CAHPS) 2.0 adult core survey. Health Serv Res 2003;38(6 Pt 1):1509-27.

24. Ware J Jr, Kosinski M, Keller SD. A 12-item ShortForm Health Survey: construction of scales and preliminary tests of reliability and validity. Med Care 1996;34:220-33.

25. Ware JE Jr, Kosinski M, Bayliss MS, McHorney CA, Rogers WH, Raczek A. Comparison of methods for the scoring and statistical analysis of SF-36 health profile and summary measures: summary of results from the Medical Outcomes Study. Med Care 1995; 33(4 Suppl):AS264-279.

26. Kadam UT, Schellevis FG, Lewis M, et al. Does age modify the relationship between morbidity severity and physical health in English and Dutch family practice populations? Qual Life Res 2009;18: 209-20.

27. DeSalvo KB, Fan VS, McDonell MB, Fihn SD. Predicting mortality and healthcare utilization with a single question. Health Serv Res 2005;40:1234-46.

28. Graubard BI, Korn EL. Predictive margins with survey data. Biometrics 1999;55:652-9.

29. Chan PS, Patel MR, Klein LW, et al. Appropriateness of percutaneous coronary intervention. JAMA 2011;306:53-61.

30. Al-Khatib SM, Hellkamp A, Curtis J, et al. Nonevidence-based ICD implantations in the United States. JAMA 2011;305:43-9.

31. Weinstein JN, Lurie JD, Tosteson TD, et al. Surgical vs nonoperative treatment for lumbar disk herniation: the Spine Patient Outcomes Research Trial (SPORT) observational cohort. JAMA 2006;296: 2451-9.

32. Weintraub WS, Spertus JA, Kolm P, et al. Effect of PCI on quality of life in patients with stable coronary disease. N Engl J Med 2008;359:677-87.

33. Kravitz RL, Bell RA, Azari R, Krupat E, Kelly-Reif $\mathrm{S}$, Thom D. Request fulfillment in office practice: antecedents and relationship to outcomes. Med Care 2002;40:38-51.

34. Marple RL, Kroenke K, Lucey CR, Wilder J, Lucas CA. Concerns and expectations in patients presenting with physical complaints. Frequency, physician perceptions and actions, and 2-week outcome. Arch Intern Med 1997;157:1482-8.

35. Hamilton DF, Lane JV, Gaston P, et al. What determines patient satisfaction with surgery? A prospective cohort study of 4709 patients following total joint replacement. BMJ Open 2013;3(4). pii:e002525.

36. Rahmqvist M, Bara AC. Patient characteristics and quality dimensions related to patient satisfaction. Int J Qual Health Care 2010;22:86-92.

37. Bain J, Kelly H, Snadden D, Staines H. Day surgery in Scotland: patient satisfaction and outcomes. Qual Health Care 1999;8:86-91.

38. Nerney MP, Chin MH, Jin L, et al. Factors associated with older patients' satisfaction with care in an inner-city emergency department. Ann Emerg Med 2001;38:140-5.

39. Mangione-Smith R, McGlynn EA, Elliott MN, McDonald L, Franz CE, Kravitz RL. Parent expectations for antibiotics, physician-parent communication, and satisfaction. Arch Pediatr Adolesc Med 2001;155:800-6.

40. Weiner SJ, Schwartz A, Sharma G, et al. Patientcentered decision making and health care outcomes: 
an observational study. Ann Intern Med 2013;158: 573-9.

41. Levinson W, Gorawara-Bhat R, Lamb J. A study of patient clues and physician responses in primary care and surgical settings. JAMA 2000;284:1021-7.

42. Young GJ, Meterko M, Desai KR. Patient satisfaction with hospital care: effects of demographic and institutional characteristics. Med Care 2000;38: 325-34.

43. Sun BC, Adams J, Orav EJ, Rucker DW, Brennan TA, Burstin HR. Determinants of patient satisfaction and willingness to return with emergency care. Ann Emerg Med 2000;35:426-34.
44. Sixma HJ, Spreeuwenberg PM, van der Pasch MA. Patient satisfaction with the general practitioner: a two-level analysis. Med Care 1998;36:212-29.

45. Hall JA, Dornan MC. Patient sociodemographic characteristics as predictors of satisfaction with medical care: a meta-analysis. Soc Sci Med 1990;30: 811-8.

46. Jackson JL, Chamberlin J, Kroenke K. Predictors of patient satisfaction. Soc Sci Med 2001;52:609-20.

47. Shadmi E, Boyd CM, Hsiao CJ, Sylvia M, Schuster AB, Boult C. Morbidity and older persons' perceptions of the quality of their primary care. J Am Geriatr Soc 2006;54:330-4. 